\title{
The Observation and Reflection on the Teaching of IELTS in Hawthorne Language Center
}

\author{
Liu Yue \\ School of International Education, Beijing Vocational College of Finance and Commerce, Beijing \\ 101101 \\ hunter2011@foxmail.com
}

Keywords: Second Language Acquisition, Teaching Method, Classroom Atmosphere

\begin{abstract}
This report introduces three hours of observation of the IELTS preparation course in Hawthorne English Center in the University of Melbourne, Australia. With detailed analysis of the teaching proceeding and methods, I examined the teachers' behavior, the advantages and limits of her methods, and aimed to provide domestic ESL teaching with reference and inspiration.
\end{abstract}

\section{Introduction}

Course phases: the 8th teaching week in the 11 weeks course. Teaching hours per week: 25

Course type: International English Language Testing System (IELTS) preparation course.

\section{Learner Analysis}

There are fifteen students in the class, including seven Chinese students, three Japanese students, three Indonesian students and two Vietnamese students. Seven male students age between 16 and 29, most of whom are around 20. All students, in the past, had already got at least 6 in IELTS test, which means they have a satisfactory grasp of English, but some wording problems still exist, such as the inaccurate, inappropriate or misleading use of the English vocabulary. They can apply and understand relatively complex language, particularly in familiar context. The aim of attending this course for most of them is to get a higher score in IELTS, which is compulsory for the admission in the postgraduate program in the University of Melbourne.

\section{Teacher Analysis}

Her teaching experience has been more than two decades. In recent years, her main area of teaching and research is ESL .Before she immigrated to Australia, in the United Kingdom she had obtained master's degrees in education and in literature. She has served as a regional IELTS examiner in Australia. Her teaching philosophy is to educate beyond exam purpose. In her mind, when she teaches English to these students whose native language is not English, she longs to help them acquire a tool of communication, rather than just passing an English exam in order to enter a university. Meanwhile, she thinks it is necessary to conduct English exams for the purpose of inspection and supervision of students' learning.

\section{Course main steps (time division):}

9: 00--9: 15 Feedback on the homework. Course starts. The first task in the morning is to examine and respond to students' homework. This is carried out through casual chat. The previous day homework is to have English conversations with five English native speakers. Students can complete the task on the bus, on the streets, in the shops, and even by telephoning the local customer service hotline. In the classroom, the teacher asks the students about the topics of their five conversations and how they feel when conducting the task. Students' feedback indicates that the conversations are very rich in subjects, mostly relevant to daily lives, such as asking for directions, shopping, banking or inquiry through hotline service. One student says the what he and 
his landlord had is complimentary dialogue of her pet dog. To further the topic, the teacher tells students that in Australia, one of the favorite topics to converse with local people is the pet. Pet owners are pleased to hear others praise their pets. Then she shares a story to exemplify people's love of the pet: on a specified day in every year, as a marketing measure, a restaurant will provide free food and drinks and invite people nearby to patron. Each table is marked with the names of the visitors. The most interesting names are those like "Luka's father" or "Bobby's mother". Such are actually the dogs' names on behalf of their owners and they are very happy to be represented by their pets. The story makes the students feel very amused. When the students talk about their own experience in completing the job, the teacher will stop the learner once she finds significant errors in the statement, and then repeat them in the original sentence until the student is aware of the errors and correct them. Some students say they speak little in the public, because they are shy or lacking in confidence in speaking English. The teacher motivates them by increasing their courage. But apparently, this sort of fear of embarrassment derived from speaking deficiency is quite common among these learners.

9: 15-9:30 Conversation between partners. Topic for discussion is "art." students were informed to look for an art-related article and summarized its main idea, and share the information in today's class with the partner, so that the two get to know each other's topic and general idea. Everyone is expected to raise two questions to test the partner, judging whether the partner fully understands the story or not. The teacher allows the students to freely group, with assistance to put students in groups with varied language background, so as to avoid the use of the same mother tongue in the task. Students are also encouraged to form heterosexual groups. The classroom echoes with light music to enliven the atmosphere. Stop of the music marks the end of the activity. The teacher shows her interest in every group, joining in the discussions or offering suggestions.

When learners are asked about their feedback, they say that they like the activity as it seems amazing to share ideas with people from different cultural background or gender group. The music creates a friendly and cheerful atmosphere, which makes all the students relaxed. All these contribute to their active participation to the task.

9:30-10:30. The whole teaching activities are designed based on an essay on the evolution of teddy bear. The teacher selects some frequently used words from the article, including: century, early, teddy bears, forehead, mouth, limbs, really bear, development, baby, in general, scientists, curious, evolution, kids, different ages, choice, baby face ,adult characteristics, asked, play, sleep, show the desire, take care of and so on. The teacher writes these words on a piece of paper. Students are divided into several groups; a representative from each group has the privilege to see these words, and try to memorize them. This is done repeatedly by different students from the same group and finally they come together to share their memories of the words. Competition is applied in this activity. After this, the teacher displays the words and encourages the students to conceive the story on their own and share it with the whole class. Reward for the best group is a little toy teddy bear. Despite the fact that most of the learners are over twenty, they are still very fond of this activity, which brings about their childhood memory. The listening task is based on the same material, which is played twice. Then the article is written on the whiteboard for the students to read, after which the teacher wipes a few words out, and lets the students read aloud, filling in these words. In this way, more and more words are wiped out and retraced from students' memory to the extent of the whole article.

This kind of training integrates the building up of vocabulary, listening, writing and speaking skills. Such an integrated task is challenging yet fruitful for teachers and students in the way that the four skills are linked with the same source of information. When the students are in a happy mood to create a story, they are also willing to listen to the recording to find the gap between their creation and the original version of the story. When they listen with previous warm-up and psychological curiosity, the effect is better for general listening exercises. On the other hand, however, this activity is time consuming, probably taking more than one hour to complete as a whole. 
10: 40-11: 10 Writing. The task in today's IELTS writing lesson is to generate a report based on a chart. In the first ten minutes, the teacher aids the students by analyzing all the contents of the chart logically to ensure that students will not miss important information in their writings. In the next ten minutes, the teacher provides exemplary sentences and vocabulary to guide the writing. Time for writing is in accordance with that in the real test.

After intensive writing task, a relaxation activity is designed, which is very interesting to observe. The teacher draws eleven simple short lines on the whiteboard, symbolic of the eleven letters in the word "immediately", which the students do not have an access. At this stage, students try to guess what letters the new word contains; if the answer is wrong, the teacher will hand paint a figure stroke by stroke, who is hanged on a tree and gradually closer to death with every vain effort in guessing the letter. Before the teacher completes the devastating painting, if the unknown word is guessed out, the students win, and vice versa, if the painting of the figure is completed, the figure died. As the painting progresses, the students are increasingly eager to get the correct answer in order to save the figure. Students respond they enjoy the game that makes dull vocabulary learning entertaining.

11: 15-12: 00 Computer Assisted Learning. The multimedia room has been installed computers with English teaching software. On the screen of the student's computer, an article with blanks to be filled in is presented. In the warm-up phase, the teacher tells the students the article is about how to make chocolate. Completing the task, students should keep the subject in their mind. Most students input "a", "the", "cream" that they know with certainty. Once students type in a correct word, the word appears in all the corresponding positions. A few minute later, the teacher reads the article and the students try to complete the article relying on their memory. Doing this repeatedly finally leads to a complete paragraph. Such computer-assisted listening exercises are very different from conventional methods.

At this stage of the course, because students are less likely to focus on what they learn due to exhaustion after long hours of learning, computer-assisted learning has positive impact as it reduces the side effect of tiredness by shifting the venue of learning, which consequently refreshes the way students learn. However, I find that some adult students are not interested in the software, and they regard it a waste of time. To some extent, it is also difficult for the teacher to control the class due to the easy access to the internet in this room.

Conclusion

The three hours of English classes run in a relatively smooth way. It's apparent that although the vast majority of students are adult learners, they are in their early 20s and are very easy to be influenced and inspired by teachers. They have a clear learning goal which is to pass IELTS, which motivates them to learn by heart. To sum up, the success of the lesson lies in the following aspects:

1. To prepare for the lesson, the teacher designed a variety of activities to improve students' overall language competency rather than simply drilling for a few hours.

2. The teacher has high English proficiency.

3. The teaching is very lively, rich in facial expressions, humorous verbal language and vivid body language. The teacher often addressed the students with "My boy", which shortened the distance between her and the students. She maintained eye contact with the students, indicating a positive or negative judge of the answers. All this makes the classroom atmosphere very friendly and motivating.

4. Multiple forms of interaction are applied, including: individual presentations, group activities, competitions, etc., to spur the learner's devotion in learning.

5. Using a variety of learning resources smartly, including listening materials, pictures, music and computers.

6. Although the course is to prepare the learner for IELTS, the teacher did not only focus on the large number of exam practices. Rather, she makes use of classroom activities in rich forms to develop the learner's English competency.

Prior to the class observation, I regard the IELTS preparatory courses as intensive drills focusing on test items. What I see in the morning session are integrated teaching and learning interactions 
with implicit goal of increasing the IELTS score. Grouping is frequently used to motivate the learners.

But it is also clear that some limits are pertinent to group works: some students lack self-discipline and are not as active as other students in participation .Some students are more used to the passive methods, such as class tests, and learn more efficiently in that way. As students are from different countries of origin, varied in ages, personalities and learning habits, the teacher must conduct in-depth research in order to design the most effective teaching programs. In my opinion, certain mandatory program is necessary, such as classroom quiz. Teachers should keep in mind that the first priority of classroom activities is to improve students' language proficiency, preferably those that can enliven the learning environment.

\section{References}

[1] Griff Griffith. How to Carry Out a Personalized Classroom Teaching, Beijing: Foreign Language Teaching and Research Press .2009

[2] Bruce, B. and A.Rubin. Electronic quills: A situated evaluation of using computers for writing in classrooms. Shillsdale, NJ:Lawrence Erlbaum. 1992

[3] Freeman, D. and J.C. Richards. Teacher learning in language teaching. Cambridge: Cambridge University Press. 1996. 